\title{
AGUA, ENERGÍA Y TELÉFONO A COMIENZOS DEL SIGLO XX EN CALI*
}

\author{
Miguel G. Camacho A.*
}

\section{Resumen}

El desarrollo de las ciudades modernas está indisolublemente ligado a la construcción de empresas de servicios públicos que puedan atender las crecientes necesidades de su población y de su eficiente prestación dependerá, en gran medida, el éxito de las urbes. En el caso de Santiago de Cali su designación como capital del nuevo departamento la llevó a emprender este proceso aceleradamente y surgieron como entidades privadas en el caso examinado aquí (acueducto y alcantarillado, energía eléctrica, teléfono), mientras que los otros (aseo y recolección de basuras, mataderos, mercadeo de víveres -o galerías-) se mantuvieron como públicas, a cargo de la municipalidad. En el período entre las dos guerras mundiales, y como reacción a la gran crisis de los treinta, el marco político planteó la necesidad de la recuperación para el Estado de todos los servicios públicos. Pero una cosa era plantearlo, otra realizarlo.

Palabras clave: historia urbana, historia servicios públicos, historia empresas de servicios públicos, Cali primera mitad siglo XX.

\begin{abstract}
The development of modern cities is indissolubly linked to the creation of publicservices enterprises that meet urban residents' growing needs. Urban successes depend greatly on the efficient provision of services. The designation of Santiago de Cali as capital of a new department, Valle del Cauca, Colombia, led it to hastily undertake this process. This case study reveals that private firms specialized in water and sewer, electricity, and telephone services. Services such as cleaning and waste management, slaughterhouses, and open-air markets [galerías] were public and in the hands of the municipality. Between World War I and II and partly due to the financial crises of the 1930s, thinking about political economy shifted, resulting igorn proposals to recover for the State all public services. It was simple to propose doing so. It was something much bigger to implement such a project and successfully finish it.
\end{abstract}

Keywords: urban history, public services history, history private firms of public services, Cali's first half of 20th Century.

¿Cuándo comienza el siglo XX en Santiago de Cali? Más que por el calendario, posiblemente en 1910, año de grandes acontecimientos para la vida del pequeño poblado que era por entonces la ciudad. Casi premonitoriamente en abril de ese

\footnotetext{
* Artículo tipo 2, de reflexión, según clasificación Colciencias. Hace parte del proyecto de investigación patrocinado por Emcali.

${ }_{* * *}$ Profesor Titular, Departamento de Historia, Universidad del Valle. Master en Historia Universidad KM, Leipzig, Alemania. C-e: camacho@univalle.edu.co
} 
año apareció el cometa Halley ${ }^{1}$ en el firmamento como otro anuncio de los grandes acontecimientos que se estaban sucediendo.

Por Decreto № 340 del 16 de abril, la ciudad fue designada como capital del nuevo Departamento del Valle, segregado del viejo "Gran Cauca" al que había pertenecido desde los primeros tiempos de la República: “...concluyó el movimiento separatista de caleños y vallecaucanos. Estaba en proceso de consolidación en el Valle, y particularmente en Cali y Buga, una elite regional y agro-comercial con afán de progreso que aspiraba al manejo y control político de la región independiente del Cauca" (Vásquez, 2001, p. 61)². Como primer Gobernador del Departamento fue nombrado Pablo A. Borrero Ayerbe y como primer alcalde, Ramón Carvajal Buenaventura. En julio, en torno a las ceremonias de conmemoración del centenario de la Independencia Nacional, se inauguró el servicio del tranvía (a vapor) que

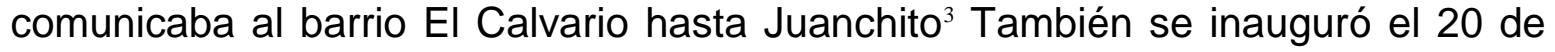
Julio la "Biblioteca El Centenario" y el mismo día se colocó la primera piedra de la Estación de Ferrocarril en la antigua estación (al sur de donde se encuentra hoy en día, construida en 1917, fue destruida por la explosión de agosto de 1956). Ese año se instaló también la estatua de fray Damián González en la plazoleta de San Francisco.

Pero dentro de la perspectiva que nos interesa, el 26 de octubre se inauguró en el sitio Piedra Grande, contiguo a la Hacienda Santa Rosa, la Planta № 1 de la Compañía de Electricidad constituida por Henry J. Eder, Edward Mason, Ulpiano Lloreda y Benito López.

La llegada de la luz eléctrica que maravilló a los pobladores, el salto del alumbrado con vela a la iluminación con bombillas en el interior de las casas; el cambio de la noche en las calles, ahora iluminadas con bujías eléctricas, dejando atrás las lánguidas y distantes lámparas de petróleo, y un poco más tarde, el alumbrado del Parque de Caicedo con esferas de cristal en lo alto de postes metálicos alrededor del parque y del kiosco, que permitió la prolongación de las retretas dominicales hasta las nueve de la noche, efectivamente debieron cambiar la mirada del mundo, la manera de concebir y vivir la noche y el día, el espacio y el tiempo, el ritmo de la vía, y las relaciones interpersonales, además de crear un espíritu optimista y una adhesión al progreso (Vásquez, 2001, p. 69 y 83).

\footnotetext{
${ }^{1}$ El cometa Halley reaparece cada 75 o 76 años.

2 Del mismo autor: (abril 1990). Historia del desarrollo económico y urbano en Cali. En Boletín Socioeconómico, $\mathrm{N}^{\circ}$ 20. También Ordóñez Burbano, L. A. (1995). Industrias y empresarios modernos, Cali 1910-1945. Cali: Universidad del Valle.; Jiménez E., Y. \& Bonilla, R. Acueducto y Alcantarillado; Cali 1910-1970. Cali: Cuadernos CITCE, Serie Investigaciones \#5.

${ }^{3}$ Véase: Calero Tejada, Á. (1983). Cali tuvo tranvía urbano. En Calero Tejada, Á. Cali Eterno; la Ciudad de Ayer y de Hoy. Cali: (s.e). También: Aguayo, A. (mayo 1988). El pintoresco tranvía que hizo la felicidad de los caleños en 1910. Despertar Vallecaucano, № 93.

${ }^{4}$ Naturalmente este acto final estuvo precedido de numerosas gestiones tendientes a obtener para la ciudad el servicio, (ver p. 69 y ss.).
} 
La aparición de la energía significó cambios en la cotidianeidad de la gente en muy diversas formas:

Yo sacaba un asiento debajo del poste de le luz más cercano a mi casa y allí me ponía a leer, Estaba estudiando en el colegio Santa Librada cuando el rector era Guillermo Borrero Ayerbe. Yo me gradué allí en bachillerato en Filosofía y Letras en el ano de 1915. Todavía recuerdo que la luz de los postes era muy tenue. Las bombillas eran pequeñitas (Estupiñan, abril de 1985, p. 33).

Ya habían existido algunos intentos por proveer de alumbrado público a la ciudad, primero mediante lámparas de petróleo y luego de alcohol, éstas últimas instaladas por el mismo Henry Eder (Ocampo, 1981, p. 145). La Compañía de Electricidad como se la conoció entonces, se llamaba realmente Cali Electric Light \& Power Co. con sede en los Estados Unidos, no sólo por la nacionalidad de Henry J. Eder sino en gran en parte por el temor que inspiraban la posibilidad de expropiación a causa de las guerras civiles (De la Pedraja, 1985, pp. 118-119) ${ }^{5}$. La compañía decía tener suscrito un capital de 200.000 dólares pero no parece que hubiera sido necesaria la inversión de todo ese capital. En 1918 se transformó en la Compañía de Luz y Fuerza Eléctrica de Cali, con sede en Colombia y continuó bajo la gerencia de H. J. Eder, su principal accionista.

Según René de la Pedraja (1985, p. 119), el Valle del Cauca se caracterizó por la rápida difusión de la generación de electricidad en las poblaciones, causada por el ejemplo y estímulo brindado por Cali al "mostrar que las plantas eléctricas se hallaban al alcance de los distintos municipios y de pequeños empresarios particulares" de manera que para 1922 las principales poblaciones contaban con sus propias plantas y otras las estaban construyendo. También debido a la mayor disponibilidad de capitales provenientes del sector azucarero y cafetero, así como por la disposición favorable en los municipios a permitir la emisión de acciones y establecer empresas municipales "para asegurar un servicio que, dado el espíritu modernizante del Valle, se consideraba indispensable".

No está por demás mencionar, que en 1913 se constituyó la Compañía de Instalaciones Eléctricas de Palmira, amparada por el acuerdo municipal del 24 de octubre de ese mismo año. El 20 de julio de 1917 se inauguraron los servicios de la planta con dos ruedas Pelton de 270 caballos cada una. La empresa tuvo mucho éxito, sin embargo, en 1926 pasó a propiedad de la Compañía Colombiana de Electricidad.

Todos estos sucesos fueron muy importantes para la incipiente ciudad, la que además, se convirtió ya desde el mismo 1910 en sede de Distrito Judicial

\footnotetext{
${ }^{5}$ Ver también: Eder, P. J. (1958). El fundador, Santiago M. Eder. Bogotá: Antares. pp. 458-459.
} 
y del Comando General Militar del Sur. Paralelamente fue erigida Diócesis el 6 de enero de 1911, según bula papal de Pío X del 7 de julio de 1910.

Las consecuencias para la ciudad no se hicieron esperar: "en el quinquenio 19101915 Santiago de Cali alcanzó una tasa de crecimiento demográfico anual del 7.033, tal vez la más alta de su historia hasta ese momento" (Vásquez, 1995, p. 10).

A inicios del siglo XX Santiago de Cali era un modesto poblado que no alcanzaba los 20.000 habitantes con un área ocupada que no pasaba de 110 hectáreas (equivalente al espacio de Univalle en Meléndez). Los barrios o sectores populares, donde habitaban artesanos, pulperos y peones (San Nicolás y el Calvario), estaban constituidos por casitas con techos de paja -eventualmente de teja de barro- y paredes de bahareque o adobe. El patriciado urbano ("Ios notables") vivían en San Pedro, La Merced y la Ermita en casas de adobe, a menudo de dos plantas, con balcones a la calle o a la Plaza Mayor, y con techos de teja. Las calles estaban "destapadas" con excepción de El Empedrado (San Pedro, La Merced, La Ermita) y por ellas corrían los "albañales" y el viejo acueducto colonial. Ello producía, especialmente en los inviernos, que se desbordaran y que las aguas para el consumo se contaminaran. La población que no disponía de las escasas conexiones con el acueducto, tomaba el agua de las pilas públicas (llamadas de Jaime, Crespo, Santa Rosa, Lores, San Pedro, San Nicolás) ${ }^{6}$. Las gentes cocinaban con leña, en las noches se alumbraban con velas y las de más alta condición social de iluminaban con importadas lámparas de petróleo.

Desde las fincas, haciendas o veredas se transportaban a Cali en mulas y caballos, los productos agrícolas para vender en los mercados semanales de la Plaza Mayor o para el consumo doméstico de los propietarios.

Con las postrimerías del siglo XIX se venían desarrollando -con cierta dinámicalas actividades comerciales y ya proliferaban tiendas, pulperías y comerciantes dedicados a la venta de productos agropecuarios producidos en sus propias haciendas o recibidas en consignación, compraventa de ganado y bienes raíces, exportaciones agrícolas (tabaco, cueros, café, etc.), importaciones de bienes manufacturados para el uso doméstico, nacionalización de mercancías, descuento de letras, créditos a corto plazo y manejo de giros, etc. Desde la segunda mitad del siglo XIX se estableció un contacto importante del Valle del Cauca con Panamá, lo cual estableció una relación peculiar que dura hasta el día de hoy. Sin embargo, la precariedad o inexistencia de caminos en el Valle constreñía el crecimiento comercial y limitaba la integración regional.

\footnotetext{
${ }^{6}$ Existen numerosas descripciones sobre ellas y su importancia en la ciudad de comienzos de siglo, por ej: Caro Copete, J. (sept 1989). Las pilas de Cali. Despertar Vallecaucano, № 99. pp. 32-33.
} 
El penoso e inadecuado camino a Buenaventura dificultaba que los productores agrícolas y los comerciantes lograran una mayor inserción en los mercados internacionales, como era su interés. La producción manufacturera durante la primera década del siglo XX era casi inexistente. No eran más de diez las pequeñas y rudimentarias instalaciones dedicadas a la producción de cigarrillos, adobes y tejas, sombreros de paño, molinos y trilladoras, jabones y velas.

Desde los primeros tiempos coloniales, el sector geográfico conocido como Valle del Cauca, sufrió ostensiblemente por su aislamiento con relación a las vías de comunicación hacia la incipiente economía mundial. El viajero Carlos Safray (1948, p. 245) ya lo había percibido con claridad a mediados de siglo XIX:

Cali es una de las ciudades más bonitas de la Nueva Granada; su posición en medio del Valle del Cauca le promete un gran porvenir, cuando un buen camino la ponga en comunicación con el pacífico. Entonces será aquella ciudad una de las plazas comerciales más importantes de la República, y en el Valle se desarrollarán todos los cultivos que convienen a su suelo y clima ... [los que] llenarán muy pronto los depósitos, acumulándose también en ellos los productos europeos que se destinan al Estado del Cauca y a otros próximos.

En la segunda mitad del siglo $\mathrm{XIX}^{7}$ y en medio de las costosas experiencias de las constantes guerras civiles del período radical, algunas mentes comenzaron a considerar el proyecto de la apertura de una moderna vía de comunicación que abriera el camino del Valle al Océano Pacífico. Numerosos fueron los intentos planeados y realizados, la inmensa mayoría fracasó debido a la dificultad intrínseca de la obra, pero también por las debilidades y dificultades políticas y económicas que afrontaba la región y el país ${ }^{8}$. La vía férrea fue avanzando muy lentamente, pero se consolidaba como la mejor alternativa de comunicación hacia el exterior?.

De esta manera, cuando el general Rafael Reyes durante su gobierno, impulsado por los deseos de introducir una reorganización administrativa del estado colombiano, planteó diversos modelos de una nueva división político-administrativa del territorio nacional y finalmente en 1910 se constituyó el Departamento del Valle -segregándolo del Gran Cauca- lo que significó la designación de Cali

\footnotetext{
${ }^{7}$ Al respecto puede verse: Vélez, H. (1996). La disolución del Gran Cauca. En Valencia Llano, Alonso (ed.). Historia del Gran Cauca, Historia Regional del Suroccidente Colombiano. Cali: Universidad del Valle.; Almario, O. (s.f.). Nuevas regiones políticas y culturales en el occidente de Colombia. En Ebenda. Florez, L. Prácticas e imágenes de modernización y modernidad en el Valle del Cauca. También: Valencia Llano, A. y Zuluaga, F. (1992). Historia regional del Valle del Cauca. Cali: Universidad del Valle.; Valencia Llano, A. (1988). Estado Soberano del Cauca; Federalismo y Regeneración. Bogotá: Banco de la República.

${ }^{8}$ Ver: Gómez Benítez, P. (1979). El Camino de Buenaventura. Cali: Universidad del Valle, Tesis Programa de Historia.

${ }^{9}$ Existen numerosas descripciones sobre la construcción del ferrocarril, algunas de ellas: Camacho Perea, M. (1981). Historia del Ferrocarril del Pacífico y las carreteras al mar. En Santiago de Cali - 450 años de Historia. Cali. pp. 219-226. Calero Tejada, Á. Cali Eterno. Op. cit, pp. 121-127.
} 
como Capital, la dirigencia regional por fin tuvo la oportunidad de incidir definitivamente en el ordenamiento del nuevo departamento y puso su empeño en la terminación de la construcción del ferrocarril del Pacífico, el cual llegó a Cali en el año de 1915. Las circunstancias habían variado extraordinariamente. Tras la guerra de los mil días, la separación de Panamá y la construcción del Canal Transoceánico, para el Valle del Cauca se imponía el acceso al Pacífico, ya no solo como una tarea importante, sino vital, de la que dependía su futuro.

Con el crecimiento de la población, del área urbana y las expectativas sobre el desarrollo inminente de la ciudad -además de los problemas de salubridad y las epidemias- aumentaron las necesidades sentidas y las demandas por servicios públicos, especialmente de acueducto, alcantarillado, energía, vías de transporte y comunicación.

Si bien en 1910 la recién creada Compañía de Electricidad inaugura la primera planta generadora de energía ${ }^{10}$, ya en 1908 el Concejo Municipal había tomado la decisión de construir el acueducto metálico y los estanques de San Antonio, cuando el cuerpo médico y la opinión pública debatieron el problema de la epidemia de tifo en la ciudad que se atribuía a las acequias destapadas y a la insalubridad del agua. En 1912 el municipio encarga a la Compañía del Ferrocarril del Pacífico los estudios para el acueducto, el alcantarillado y la pavimentación, los que se adoptan en 1913. Y en 1916 se crea la Junta Constructora del Acueducto, como entidad delegada para adelantar la dirección de la obra, manejar los recursos asignados por el municipio y adelantar las contrataciones.

El 19 de enero de 1915 la línea férrea llegó a Cali. Con ello comenzó un proceso de crecimiento de las importaciones y de las exportaciones, especialmente las cafeteras (Ocampo, 1981, p. 129). El grano de exportación que antes salía del Quindío y del norte del Valle preferentemente por el río Magdalena para ser despachado en Barranquilla, comenzó ahora a tomar la ruta fluvial del río Cauca a Cali (desde La Virginia a Juanchito, luego a Puerto Isaacs), y de aquí por el ferrocarril a Buenaventura, puerto que fue dotado de un muelle nuevo, construido entre 1919 y 1922 , pero que se dio al servicio desde 1920 .

La creciente movilización del café exportado por Buenaventura vía Cali, impulsó una serie de actividades de embarque, desembarque, bodegaje y transporte en la ciudad. La salida al mar por Buenaventura se convirtió en la salida natural para toda la producción cafetera del occidente del país, ya que la comunicación con el río Magdalena siempre estuvo aquejada de contratiempos y los altos fletes; a lo

\footnotetext{
${ }^{10}$ La planta tenía una capacidad de 50 Kw. con un aforo de aguas mínimo de 800 lts./min. y una caída de 62 metros.
} 
que se unió (en décadas posteriores) el poderío del sindicato de braceros del río. Todo ello hizo que el comercio de café se orientara por el Valle del Cauca hacia el exterior y de allí la enorme importancia de Buenaventura para el país. Casas exportadoras del grano, generalmente de propietarios «paisas» se instalaron en Cali, pero además se desarrollaron actividades conexas como la hotelería y se activó el comercio. Exceptuando La Garantía, fundada en 1915, el reducido número de pequeñas y rudimentarias fábricas que aparecieron en este período, utilizaban como insumos los productos agropecuarios de la región para producir bienes de consumo doméstico (cigarrillos, jabones y velas, chocolates, lácteos, hielo, calzado, molinos y trilladoras).

En esta época se construyeron o se adecuaron caminos que vincularon a Cali con su espacio rural más inmediato, permitiendo un mejor acceso de los productos agrícolas a los mercados de la ciudad (hacia La Balsa, Candelaria, La Torre y Navarro).

También, ante el atraso en materia de salubridad (epidemias e infecciones) y la necesidad sentida de modernizar a Cali, se acometieron obras de servicios públicos, unos manejados por empresas privadas (energía y teléfonos) y otros por el municipio directamente (alcantarillado) o por delegación en una junta (acueducto). Gradualmente, y asociada a la modernización y al crecimiento de los recursos municipales, se amplía la cobertura escolar. De manera que se inicia un proceso de dotación de servicios públicos que inciden en el bienestar de los habitantes, acciones que incidieron en un aumento de la esperanza de vida.

En este período se crea el barrio Obrero, se desarrolla el barrio El Piloto que en los comienzos de siglo era un pequeñísimo caserío disperso en la zona ejidal, aparece el barrio Jorge Isaacs en el lado oriental de la vía férrea y el barrio Granada "al otro lado" del río Cali en el norte, estos dos últimos rompiendo las barreras del río y de la línea del ferrocarril.

\section{Los servicios públicos}

En cuanto al acueducto "**, "hasta fines del siglo XIX el alcantarillado consistía en acequias, descubiertas en parte, o tapadas con lajas de piedra alargada, como lo recomendaba la municipalidad, que pasaban por el centro de la calle, en tanto que el acueducto pasaba por el centro de los solares" (Giraldo, 1981, p. 166). Al comienzo del siglo XX existía una acequia que conducía al agua para consumo por una mampostería construida con piedra y calicanto que tomaba sus aguas del río Cali al occidente de la Hacienda Santa Rosa, en el sitio conocido como Santa Rita, recorriendo la pendiente de los cerros, caía de nuevo al río para formar el "charco

\footnotetext{
${ }^{* * *}$ Los subrayados son del autor.
} 
del burro" y bajaba a la carrera $4^{a}$ donde se desprendían diversos ramales que conducía a las pilas, donde los habitantes se surtían de agua: Pila de Jaime, de Crespo, de Santa Rosa, del Matadero, de la Chanca, de Lores, de Belalcázar, de Buenaventura, González ${ }^{11}$.

En 1903 se planteó en el Concejo la necesidad de construir un acueducto metálico ya que la acequia abierta existente era un peligro para la salubridad (Fajardo, julio 11 de 1921, pp. 145-148), pero tan solo en 1912 se ordenó finalmente su construcción, con base a los estudios realizados por la Empresa del Ferrocarril del Pacífico. La construcción inició en 1916, tras acordarse que lo construyera el Distrito de Cali $^{12}$ y contemplaba tres obras: el canal de conducción, dos tanques en San Antonio y la red metálica de distribución, los cuales se construyeron entre 1918 y 1919. La red metálica continuó extendiéndose, para concluir su programación en 1928, favorecida por la gran actividad constructora de la segunda mitad de los años veinte (nutrida en la superación de la crisis que se presentó mundialmente inmediatamente tras el fin de la primera guerra mundial y el consecuente activo comercio de artículos de metal: las siderurgias buscaban afanosamente mercados); así, se pasaron de 2.118 instalaciones en 1922 a 6.624 en 1931. A pesar de que los estanques de San Antonio sólo servían de almacenamiento y solo más tarde de sedimentación, se observa una reducción de la tasa de mortalidad (defunciones/población total). Esta reducción había sido mayor si se hubiese dispuesto de planta de purificación y se hubiese controlado el expendio de "leche cruda" en la ciudad, lo que hacía susceptible a la población a contraer enfermedades ${ }^{13}$ La ciudad quedó de todas maneras habilitada para suministrar teóricamente agua a una población de 160.000 habitantes con un consumo de 200 litros día habitante, en un momento en que la ciudad no llegaba a los 35.000 pobladores $^{14}$.

Respecto al alcantarillado se realizaron obras y se extendieron redes (paralelas a las del acueducto) en desarrollo de lo ordenado por el Acuerdo 13 de 1913. Sin embargo, resultaban insuficientes frente a la expansión de la ciudad y al creciente suministro de agua que carecía de los desagües necesarios para conducir y disponer finalmente las aguas usadas. En 1922 se firma el contrato para la financiación y construcción del alcantarillado, suscrito entre el Municipio y

\footnotetext{
${ }^{11}$ Una descripción detallada y el plano de su localización se encuentra en: Vásquez B., Edgar, Historia de Cali en el siglo XX..., ob. cit., p. 103-5. También Calero Tejada, Álvaro, Las viejas pilas de Cali, en: Cali Eterno, s.d., p. $145-148$.

12 "La experiencia ha demostrado que los privilegios concedidos a compañías particulares, para empresas de esta naturaleza... no dan los resultados satisfactorios para los intereses de la comunidad." Acuerdo $\mathrm{N}^{\circ} 18$ de 1915.

13 "Estas enfermedades (intestinales y fiebre tifoidea) han disminuido aunque no han desaparecido totalmente, siendo raros 1os casos de fiebre tifoidea..." Fajardo, J. Municipio de Cali..Op.cit.; también, Vásquez et all. Periodización y relaciones..., op. cit. p. 16.

${ }^{14} \mathrm{La}$ experiencia de construcción del acueducto fue naturalmente bien significativa para la ciudad y sus gentes, como se desprende de las memorias y relatos consignados en Cali Eterno y en Despertar Vallecaucano.
} 
Alfonso Vallejo y que debía ser pagado con una emisión de bonos. Sin embargo, hubo un rezago de las obras de alcantarillado respecto a las del acueducto, rezago que subsistió hasta los comienzos de los años 40 . Con el paso de los años se logró construir un sistema de recolección de aguas servidas y pluviales, pero éstas terminaban en las quebradas y ríos que circundaban la ciudad produciendo situaciones de inundación y alarmas sanitarias.

El crecimiento de la ciudad llevó a que la recolección de las basuras y el aseo del área urbana se convirtieran en una preocupación social. En 1910 se estableció el servicio oficial de recolección y eliminación de basura (Acuerdo № 4 del 16 de mayo) y en 1920 se buscó crear las condiciones para su depósito en un lote en las afueras. Finalmente en 1926 este servicio terminó siendo adscrito a la Oficina de Sanidad Municipal.

El servicio de teléfonos se inició el 19 de agosto de 1912, gracias a la labores emprendidas por Emmanuel Pinedo, nacido en Venezuela y de origen hebreo, quien gracias a la concesión obtenida del Concejo (Gaceta Municipal, № 544, 9 de abril de 1939) ${ }^{15}$, adelantó negociaciones con la Stromberg Carlson Corporation para instalar una planta telefónica manual y en base a baterías eléctricas. Sin embargo el Sr. Pinedo no guardaba relación contractual alguna con el Municipio de Cali. Se instaló la primera planta de escritorio en el local de la esquina de la calle 12 con carrera 7, de donde salían lo alambres (inicialmente de hierro, luego de cobre) que eran sostenidos por postes de guadua. El servicio tuvo pronto gran acogida y para 1919 contaba con 350 usuarios (siete veces el número original), sin embargo, la expansión se realizó por el servicio de líneas compartidas y no por ampliación de la central. De todas maneras en los años veinte se instalaron líneas abiertas para teléfonos en haciendas en jurisdicción de Palmira y de Yumbo. En 1921 Palmira ya contaba con una planta y 21 líneas (Boletín de Estadística Departamental, enero 2 de 1922, p. 180).

En 1924 se gestionó en el Concejo un contrato para construir una red subterránea y eliminar la red de postes de guadua (la corriente modernista de ciertos sectores de la ciudad criticaban su estética). El permiso fue concedido a la Empresa de Teléfonos de Cali y se reconocía los derechos del Sr. Pinedo sobre ella; pero a la vez, se la obligaba a cumplir con impuestos y gravámenes municipales (Acuerdo 45 de 1924$)^{16}$.

\footnotetext{
${ }^{15}$ Acuerdo No 9 del 19 de agosto de 1912: "Contratos relacionados con la Empresa Telefónica". Las normas allí estipuladas sobre condiciones para la prestación y uso del servicio fueron muy importantes posteriormente. Edgar Vásquez lo anota: "Cierto sentimiento nacionalista que, tal vez, se prolongó a partir del episodio de la separación de Panamá, y una alta valoración que -con razón o sin ella—se le asignaba a "lo público" por su función social, eficiencia y apoyo al desarrollo de las actividades económicas del sector privado, se pueden observar en las decisiones que tomaban los dirigentes locales en materia de servicios públicos". Historia de Cali.., Op. cit., p. 116.

${ }^{16}$ Este acuerdo insiste en impedir el acceso del capital extranjero en la propiedad de la empresa, reivindicando
} 
El inusitado crecimiento que sufrió la ciudad en los años veinte hizo que hiciera indispensable a finales de la década del veinte una planta moderna y automática. El Sr. Pinedo entabló conversaciones con la empresa Automatic Electric Center de Chicago y en 1930 se firmó un contrato de asociación entre las dos empresas de la cual surgió la Compañía de Teléfonos del Pacífico; la compañía pasó de hecho a manos de la compañía norteamericana. El comienzo de la gran crisis mundial de los treinta no permitió realizar la compra de una planta automática. Entre tanto, en 1927 se negociaron los términos del acuerdo entre el municipio y la empresa (mediante Acuerdo № 49 del 26 de junio). De esta manera, si bien la propiedad se mantenía en manos privadas, representadas en el Sr. Pinedo, el Municipio entraba a cobrar un porcentaje de participación de los ingresos brutos (primero 8 y luego $10 \%)$ por utilización de espacios y bienes públicos.

En los años diez no se montaron plantas de generación eléctrica adicionales a la del río Cali № 1 . Para 1920 se habían culminado los ensanches "pero la Compañía de Luz y Fuerza Eléctrica entró en una etapa de estancamiento, con el resultado de que por varios decenios el desarrollo eléctrico estuvo rezagado con relación al acelerado crecimiento de la demanda... Quizá por haber concentrado sus esfuerzos en la introducción de sistemas eléctricos a los ingenios, los azucareros perdieron el interés en la empresa de energía que enfrentaba los consabidos problemas de cómo financiar ensanches que sólo eran rentables a largo plazo; tal actitud facilitó su adquisición por la Compañía Colombiana de Electricidad en 1927." (De la Pedraja, 1985, p. 119). El Cali rural no siempre se entiende con el Cali urbano.

Entre tanto, habían comenzado a utilizar energía eléctrica algunas fábricas y talleres. Para 1918 se registraban los siguientes grandes clientes: "Dos trilladoras, una fábrica de cerveza, dos fábricas de puntillas, una fábrica de chocolates, una fábrica de hielo, tres Trilladoras, tres gabinetes dentales, cuatro de pan, seis bombas de levantar agua, un molino de sal, dos peluquerías con esterilizador, un taller de madera"17.

Como se puede colegir, inicialmente tanto la generación, como la distribución de energía eléctrica, al igual que la instalación del servicio telefónico fueron proyectos adelantados por particulares con concesiones del Concejo, mientras que el Municipio asumió la financiación y la prestación de los servicios de acueducto, alcantarillado, aseo y recolección de basuras.

\footnotetext{
el interés nacional en los servicios públicos.

${ }^{17}$ Ver: Vásquez, E. et all. Periodización y relaciones..., op. cit., p. 16 y 17 y Ordóñez, L. A. Op. cit., pp. 5863.
} 
En cuanto a energía eléctrica, en 1924 se hizo el montaje de la sub-estación de San Antonio en los predios de los tanques del acueducto, y el 10 de febrero de 1926 la Compañía Colombiana de Electricidad (CCE) inaugura y pone en marcha la Planta Rio Cali $N^{\circ}$ 2, tres kilómetros arriba de la primera, con 1000 $\mathrm{Kw}$ de generación. En agosto del año 1928 la empresa fue adquirida por el conglomerado norteamericano Bond and Share que en 1929 instaló la Planta Diesel I y en 1931, la Diesel II. La Compañía Colombiana de Electricidad era una filial de la South American Power Co., parte del conglomerado Bond and Share (Vásquez, 2001, p. 217).

También la planta de Meléndez, que funcionaba para uso particular del molino de la Compañía de los señores Gómez y Robayo, con 400 Kw., fue adquirida el 24 de junio de 1930 por la CCE e integrada al servicio de la ciudad.

El servicio de generación de energía se mantuvo estacionario, a la par que el crecimiento demográfico fue de 1.6 entre 1930 y 1938 lo que llevó a que el servicio terminara siendo deficitario y presentara numerosas interrupciones provocando numerosas críticas en la opinión pública de la época ${ }^{18}$.

En los años veinte, al igual que ocurrió a nivel nacional, ingresan al Departamento del Valle y a Cali importantes recursos de crédito externo. El más importante empréstito del municipio en este período fue el que se realizó en 1927 con la Baker Kellogg \& Co. Inc. de New York, con destino a la construcción del acueducto. Simultáneamente el municipio autorizó una emisión de bonos por cinco millones de pesos a veinte años y al $7 \%$. Con anterioridad para adelantar las obras del acueducto, el alcantarillado y el teatro Municipal se había recurrido a crédito interno: emisión de $\$ 200.000$ en bonos de colocación interna en 1918 y en 1921 , crédito otorgado por Alfonso Vallejo para el alcantarillado por $\$ 180.000$ en 1925. En 1928 el municipio de Cali logró una realizar una captación de recursos por $\$ 450.000$ al $9 \%$, con un año muerto, y sin garantía de ninguna clase, dado el cumplimiento de sus obligaciones anteriores. Un tercio de este monto lo otorgó el Royal Bank of Canada, otro tercio el Banco de Colombia y el resto el Banco Alemán Antioqueño, estos recursos fueron utilizados para comprar la plaza de mercado y el matadero público a la Compañía de Obras Públicas del Cauca que las había entregado para su explotación a un particular.

En este período se realizan en el Valle una serie de obras viales de gran importancia para el desarrollo de Cali y la región: la carretera Central Cali - Cartago (concluida en 1927), el puente Carlos Holguín sobre el río Cauca (en el hoy Juanchito), el tramo Cali - Saladito de la carretera a Buenaventura y la carretera Armenia - Ibagué, financiada por el Ferrocarril del Pacífico, que conectó

\footnotetext{
${ }^{18}$ Ver por ej. Diario del Pacífico. (julio 26, agosto 22, septiembre 13 de 1941).
} 
este ferrocarril con el de Girardot - Tolima - Huila. Este punto fue de vital importancia, ya que obtuvo el acceso de los productos vallecaucanos (azúcar, cacao) al mercado del centro del país y facilitó el ingreso al Valle de algunos productos del centro del país que antes se importaban o se adquirían desde el interior con muy altos costos de transporte (como en el caso del cemento) (Vásquez, 1995, p. 45).

\section{El desarrollo urbano}

En estos años se construyen el Hospital Club Noel, el Cuartel del Batallón Pichincha donde hoy se encuentra el Centro Administrativo Municipal -CAM-, el Matadero del Municipio, el Hotel Alférez Real, el Edificio Otero y se inicia la construcción del Palacio Nacional.

Además, se acelera el crecimiento de la actividad comercial y aparecen fábricas productoras de alimentos (cervecería Los Andes, fideos La Espiga de Oro, Dulces Colombina), textiles (Calcetería Mariela, Industria de Textiles Colombia), materiales de construcción (Tejares Santa Mónica), también jabones y velas (Ulpiano Lloreda y Guillermo Acevedo), fósforos (fábrica de Fósforos "Radio"), los Laboratorios Jorge Garcés B. (JGB), la Armería y Mecánica (Martínez \& Tarruz). La construcción, la trilla y movilización del café de exportación, el acelerado desarrollo comercial y la industria incipiente, generaron un rápido crecimiento (Posada, 1918).

El número de viviendas aumentó a una tasa anual del $8.86 \%$. en tanto que el ritmo de crecimiento del área urbana (1.44) fue inferior. Por tanto aumentó la densidad de viviendas de 12.41 en 1922 a 19.0 unidades por hectárea en 1928. Sin embargo se presentó una expansión del área urbana. Surgen los barrios Centenario y Juanambú para ampliar el desarrollo "al otro lado del río" iniciado por el barrio Granada, y se amplían el barrio Obrero y Jorge Isaacs que ya había iniciado la ocupación "al otro lado" de la línea férrea. De igual manera surge la urbanización San Fernando que nació en 1927 construida con la más depurada técnica de entonces: "la Compañía constructora colombiana, cuyo verdadero nombre era Colombian Holding Corporation fue la primera empresa en intentar construir un barrio residencial, siguiendo las especificaciones que para estas obras se usaban en los Estados Unidos y que son muy exigentes y rápidas. El actual San Fernando quedaba lejísimos de Cali entre el barrio de La Chanca, actualmente San Bosco y el lugar escogido para levantar las viviendas solo existían llanos y montículos salvajes" (Despertar Vallecaucano, № 20, mayo - junio 1987, p. 20). Los planos generales de la construcción fueron aprobados por el Consejo Municipal y las especificaciones de sus obras urbanísticas eran de las más modernas: "de modo que el nuevo barrio fuera atractivo, no sola- 
mente por las condiciones higiénicas, por la clase de construcciones, por la amplitud de sus calles y otras muchas ventajas, sino también porque sería el más pintoresco de la ciudad. El alcantarillado se hizo obedeciendo a estudios hechos por ingenieros competentes y antes de iniciar la construcción de los edificios, algo absolutamente inusual para la época. Para la provisión del agua potable el Acueducto Municipal construyó un ramal que iba directamente de los estanques a la urbanización. ... Conviene observar que en las construcciones no se emplearon para nada adobes o bahareques: todas las divisiones fueron de ladrillo con los respectivos repellos con mezcla a base de cemento... Se organizó una compañía que puso un servicio de transportes, especial para la urbanización, con itinerario fijo, precios bajos y vehículos apropiados a las varias necesidades..." (Despertar Vallecaucano, № 20, mayo - junio 1987, p. 20) ${ }^{19}$. El desarrollo de la urbanización San Fernando marca un hito en la modernización de las prácticas urbanísticas, arquitectónicas y constructivas de la ciudad y su aparición dejó huella indeleble en la conciencia de los ciudadanos caleños

Así, continuó el proceso de urbanización demográfica y superficiaria, más intenso el primero que el segundo, debido a la densificación de la población urbana: entre 1922 y 1928 la tasa de urbanización demográfica pasó del 57.4 al $65.8 \%$, en tanto que la tasa de urbanización superficiaria se elevó de 0.50 a 0.54 (Aprile-Gniset, 1992, p. 123).

La ciudad aumentó la población y se amplió hacia algunas áreas distanciadas ahora del tradicional casco colonial; la nueva ciudad (tímidamente moderna) comenzó a separarse claramente de su pasado cercano. A la par, la población tenía ya unas mayores expectativas y aspiraciones respecto al mejoramiento de las condiciones de vida. Los diversos sectores de la ciudad aspiraban a una creciente modernización de la ciudad, con servicios públicos adecuados al nuevo tipo de viviendas, y comerciantes y fabricantes urgían por servicios públicos que permitieran un mayor desarrollo de las actividades empresariales. Es en este contexto que se realiza la segunda etapa de extensión del acueducto metálico que logró una amplia cobertura, y se construye un estanque de agua adicional en San Antonio, a la vez que se proyecta la planta de purificación. Se inicia, pues, un período de gran abastecimiento de agua y el consumo se amplía.

Pero además, se desarrollaron obras de alcantarillado que, aunque deficiente y sin solución a la disposición final de las aguas negras, para 1929 ya había cubierto todo el "casco viejo" de la ciudad. En 1913 el municipio inicia algunas obras con

\footnotetext{
${ }^{19}$ Allí se pueden apreciar unas muy interesantes imágenes del este barrio recién construido. La empresa de autobuses lleva su nombre.
} 
base en los estudios encomendados a la compañía Ferrocarril del Pacífico, pero es en 1922 cuando se aceleran estos trabajos y se celebra un contrato de financiación y construcción con Alfonso Vallejo para adelantar algunas obras de alcantarillado y pavimentar algunas calles, además de otro contrato con G. Garcés y Arboleda.

Tal como lo describe Edgar Vásquez "entre la entrada del Ferrocarril a Cali y la crisis de 1930 despuntó de manera muy incipiente el capitalismo. El germen del crecimiento industrial, dentro de un entorno económico y social predominante premoderno se nutrió de demandas que en gran parte, procedían de Ingresos generados por actividades precapitalistas. ... Pero, además, este proceso ocurrió en un contexto de una mentalidad compleja que oscilaba o combinaba la tradición y la modernización. La sociedad provinciana con fuerte arraigo religioso y moral en el catolicismo aspiraba a vincularse con el mundo desarrollado y sumarse a la marcha del progreso. No eran pocos los que deseaban para Cali unos diseños urbanísticos y unas tecnologías modernas propios del capitalismo de la época pero, a la vez, censuraban sus necesarios efectos sobre los comportamientos, las actitudes y la moralidad" (Vásquez, 2001, p. 91).

\section{La expansión de la ciudad: 1930-1945}

La crisis mundial «de los treinta» afectó a Colombia ${ }^{20}$ y llevó a que se suspendieran los grandes flujos de crédito externo que el país venía recibiendo desde el período anterior, conocido en la historiografía como la "danza de los millones". Esta circunstancia produjo una difícil situación financiera y fiscal del gobierno y consecuentemente, se suspendieron las obras públicas que se venían adelantando durante los períodos anteriores ${ }^{21}$.

La gran crisis interrumpió bruscamente el proceso de crecimiento económico que venía ocurriendo con celeridad en Cali durante el período anterior (1922-1928). La suspensión del flujo de recursos externos, sumada al deterioro de los recaudos arancelarios, imposibilitó a la nación continuar realizando obras públicas en las regiones.

Aunque la carga de café movilizada a través de Cali continuó creciendo y por lo tanto no debieron afectarse sensiblemente las actividades que se realizaban en

\footnotetext{
${ }^{20}$ Véase, por ej.: Posada Posada, C. E..(1989). La gran crisis en Colombia: el periodo 1928-1933. En Nueva Historia de Colombia (NHC), Vol. V. Bogotá: Editorial Planeta. pp. 77-102.; Ocampo, J. A. \& Montenegro, S. (1982). La crisis mundial de los años treinta en Colombia. En Desarrollo y Sociedad, No 7.; Rodríguez, O. (1973). Efectos de la gran depresión sobre la industria colombiana. Bogotá: Tigre de Papel.

${ }^{21}$ Ver: Ocampo, J. F. (1984). Colombia y la economía mundial, 1830-1910. Bogotá: Siglo XXI Editores.; Kalmanovitz, S. (1985). Economía y Nación. Bogotá: Siglo XXI Editores.
} 
torno al grano de exportación, de todas maneras, muchas obras que el Ferrocarril del Pacífico realizaba en el Valle y en Cali, fueron suspendidas. Pese a ello, con algunas limitaciones, se adelantó la construcción de los talleres de Chipichape bajo la expectativa expresa de la próxima recuperación económica que requeriría un equipo rodante en buen estado. Dada la capacidad de gestión, la disponibilidad de recursos humanos y técnico, la Empresa del Ferrocarril del Pacífico se había convertido en actor fundamental para el diseño y construcción de obras ajenas a sus propias funciones, como fue el caso del plan de acueducto, alcantarillado y pavimentación de Cali, o la construcción del Palacio Nacional.

En estas condiciones, el descenso de la demanda local y de los precios interrumpió el comportamiento dinámico del comercio y el incipiente desarrollo manufactureros; así, por ejemplo, entró en liquidación las Industrias Textiles de Colombia que pasó en su totalidad a propiedad de Jorge Garcés Borrero (J.G.B.) con mayor capacidad financiera para esperar la recuperación. Además, "por primera vez desde la fundación de Carvajal \& Cia. (1904), no se pudieron atender las obligaciones comerciales y ni siquiera cubrir los intereses de las deudas que pesaban sobre ella" (Castrillón, 1981).

En esa coyuntura convulsa, la Cámara de Comercio solicitó al gobierno nacional reiniciar las obras públicas suspendidas, en tanto que en el Concejo Municipal se suscitaron debates sobre la manera de afrontar la crisis local. El debilitamiento de la demanda local también provocó, entre 1929 y 1931, un descenso del $66.3 \%$ de la gasolina importada y una caída del $39.2 \%$ de las manufacturas introducidas a Cali desde el exterior. El descenso del producto interno de Cali se reflejó en el recaudo Municipal que a su vez incidió en la caída del gasto del Municipio. Incluso el descenso del producto de Cali impactó el crecimiento demográfico y físico de la ciudad: la tasa de crecimiento anual de la población urbana que en el período anterior había sido $7.47 \%$, ahora en la crisis.

En este período siguen desarrollándose en el occidente, al "otro lado" del río Cali, los barrios Granada, Juanambú y Centenario, en tanto que en el sur se inicia el poblamiento y conformación del barrio Alameda.

\section{Los servicios públicos}

Las obras de acueducto, que desde 1927 estaban financiadas con el préstamo de la Baker Kellogg, no se suspendieron durante la crisis mundial y es así que en 1931 se termina la Planta de Purificación en San Antonio y se avanza en el tendido de la red matriz al oriente; la planta incrementó su capacidad de purificación de $0.370 \mathrm{M} 3 / \mathrm{seg}$. a $0.476 \mathrm{M} 3 / \mathrm{seg}$. Si bien entre 1929 y 1933 se presentó un crecimiento anual de suscriptores (144\%) y consumo (150\%), su ritmo fue inferior al del período anterior. "Los trabajos del acueducto se realizaron entre 1915 y 1927 y se 
construyó una bocatoma sobre el río Cali, en la parte llamada "Santa Rita", ubicada muy cerca actualmente de la planta eléctrica № 1. La longitud del canal abierto tuvo una extensión de 4.200 metros, se construyó un tanque de sedimentación y se instalaron unas pocas cañerías y tuberías en la ciudad. Entre ellas gozaron las primeras puestas los barrios El Penón y San Antonio. Al insigne ingeniero Sebastián Ospina le tocó construir parte de esta obra, que es una joya con que cuenta nuestra querida" (Despertar Vallecaucano, No 103, agosto 1990, p. 34). Durante la crisis la ciudad tuvo un nivel de abastecimiento bastante satisfactorio. Pero, además, se puede atribuir a la planta de purificación (1931) construida en San Antonio efectos favorables sobre las causas de mortalidad. Pero el progreso no llega sin algunas tribulaciones:

Todo tiene algo insólito y éste es mi cuento. Se debió de conseguir un ingeniero y algunos técnicos en hidráulica para encargar a ellos la ejecución del acueducto. A mediar 1929, la obra estaba prácticamente terminada y listo el canal para conducir el agua hasta el lugar, y decidieron probar el trabajo llenando los tanques. Resulta que todo anduvo bien hasta que se empezaron a notar humedales y filtraciones que aparecieron hasta en el parque de Santa Rosa. Alguien hizo circular la especie de que esos tanques no tenían la consistencia deseada, y que de un momento a otro se iban a estallar, y en avalancha feroz acabarían con más de medio Cali, arrasando con lo que se encontrara a su paso. Con semejante noticia cundió la alarma, y se caldearon los ánimos a tal punto que el pueblo decidió cobrarle la maldad al mister que habla tenido a su cargo la construcción. Dicho señor vivía en una pensión que en Cali tenia una dama de nombre Nieves Zorrilla, por allá por la Calle 14 con tercera y cuarta. Ya el pueblo enfurecido con Palos y piedras se dirigía a despedazar al pobre gringo. Pero alguien se adelantó previendo lo que iba a pasar; de alguna manera, el mister se saltó una tapia escondiéndose en la vecindad, Cuando llegó la turba enfurecida, dona Nieves autorizó a unos pocos a que entraran y se dieran cuenta que el señor no estaba y decidieron entonces buscar a don Isaías Mercado, quien a la sazón era el Gerente, y buscarle problema. En esas llegó la noche, la gente desmoralizada se fue dispersando, dejaron los palos en reguero en el parque de Cayzedo, y se calmó la situación. Pero el escándalo fue a dar al Concejo, donde se culpaba a -raimundo y todo el mundo-, del gran peligro latente, que era el tal acueducto.

Como estaban en prueba los famosos tanques, decidieron desocuparlos, y buscar los servicios de otro ingeniero experto en impermeabilizar esta clase de depósitos. Así se hizo y en la segunda llenada la cosa tuvo éxito y de esto hace ya varios lustros y jamás se volvieron a ver filtraciones ni volvió a causarle preocupación a nadie en este burgo de don Sebastián.

El propio presidente Olaya abrió la llave maestra del acueducto, y nos consta, a la generación que presenta la nieve del tiempo cubriendo sus sienes, como en el tango de Gardel, que de esta agua si beberé, he bebido y seguiremos bebiendo hasta que nos lleven a la primera con veintiséis, y eso si no quedamos de pronto en un paraje inhóspito convertido en camposanto, como a veces suele suceder (Aparicio Navia, dic 1996-ene 1997, p. 18). 
Por otra parte, las obras de alcantarillado avanzaron muy lentamente en desarrollo de redes separadas con vertimiento en cauces naturales de agua.

En el servicio de energía ocurren cambios importantes: como ya fue descrito, la Compañía Colombiana de Electricidad (CCE) filial de la South American Power Company compró la Empresa de Luz y Fuerza Eléctrica (el 10 de agosto de 1928) y al año siguiente inauguró la planta Cali-Diesel. Luego, en 1930 adquirió la planta hidroeléctrica del río Meléndez e instaló tres circuitos de distribución, uno de ellos aéreo (río Cali-El Peñón) y dos subterráneos (El Peñón-Hospital de San Juan de Dios y Hospital San Juan de Dios-El Peñón). Después de instalada la planta Diesel 1 en 1929, la capacidad de generación no aumentó durante la crisis, pero era satisfactoria.

El servicio telefónico no elevó la capacidad de líneas en equipo y el crecimiento de los suscriptores se logró a través de líneas compartidas: "Bien podría afirmarse que la década de los años treinta fue una década muerta en materia de oferta telefónica" (CIDSE, s.f., p. 14). Durante la crisis la cobertura descendió: en el período 1922-1931 la cobertura fue de $7.85 \%$, en tanto que para el período 1931-1938 descendió a $5.25 \%$.

Los teléfonos -de sistema manual- cubrían el 5.2\% de las viviendas. El alcantarillado, aunque con una cobertura espacial relativamente amplia, presentaba problemas relacionado con la combinación de aguas sanitarias y pluviales, taponamientos, filtraciones y sedimentaciones, además de que se ampliaba la brecha entre la cobertura del acueducto y la del alcantarillado.

Los servicios de energía y acueducto eran bastante satisfactorios para la época: en 1931 existía una capacidad de generación eléctrica de $3.400 \mathrm{Kw}$. mientras el pico de consumo llegaba a 900 Kw., situación que utilizó la Compañía Colombiana de Electricidad para promover y vender estufas, planchas y neveras.

Al terminar la tercera década del siglo $X X$, los servicios de energía y teléfonos eran manejados por compañías privadas, en tanto que los servicios de acueducto y alcantarillado corrían a cargo del Municipio de Cali.

En 1930 la Automatic Electric Company de Chicago compró el 50\% de las acciones de la vieja empresa telefónica creada y de propiedad de Emmanuel Pinedo e inaugurada en 1912. A partir de 1930 la compañía extranjera adquirió gradualmente el resto de las acciones, momento en el cual toma una nueva razón social: Compañía Telefónica del Pacífico.

El desarrollo de la infraestructura de los servicios, la magnitud de la población servida que venía en proceso de crecimiento, la mayor complejidad de la administración municipal que se encargó del matadero público, la plaza de mercado, y la necesidad de crédito interno para financiar los servicios, plantearon la necesidad de superar las formas de manejo de servicios administrados separadamente y de crear una organización diferente. En 1930 (Acuerdo № 9 del 11 de marzo) el Concejo determinó que las tres empresas existentes, el Acueducto Municipal, la Plaza 
de Mercado y el Matadero fueran administradas por el Gerente de las Empresas Municipales nombrado anualmente y en 1931 el Acuerdo № 13 delega la administración de las empresas en una Junta constituida por tres miembros: así se "constituyó prácticamente el origen de las Empresas Municipales de Cali" (Vásquez, 2001, p. 126).

\section{El acuerdo de creación de las empresas municipales}

Hasta 1931 hay que considerar dos aspectos relevantes: a) la importancia que adquirió la banca interna para el desarrollo de los servicios, especialmente en un período de crisis con descenso del crédito externo y de la reducción de las transferencias del gobierno central. b) la complejidad de la administración municipal al manejar, además de los servicios de acueducto y alcantarillado, los de la plaza de mercado y el matadero público, en tanto que el alcantarillado estaba adscrito al Departamento de obras de la Alcaldía.

Estos dos aspectos contribuyen a explicar el sentido del Acuerdo Municipal $\mathrm{N}^{\circ} 13$ de agosto de 1931 que creó las "Empresas Municipales" asignándole el manejo del Acueducto Municipal, la plaza de Mercado Público, el Matadero, la administración y recaudo de los impuestos de Espectáculos y de alcantarillado. Además, por delegación especial, constituyó una Junta Administradora con miembros elegidos cada dos años, entre los cuales figuraban representantes de las entidades bancarias acreedoras del Municipio. La Junta Administradora manejaría las empresas durante doce años y las "Empresas Municipales" tendrían personería jurídica para celebrar actos administrativos, contratos y adquirir en nombre del Municipio los derechos y obligaciones que se desprendiesen del desarrollo y cumplimiento de sus funciones. Pero el Concejo Municipal se reservaba el derecho de fijar las tarifas de los servicios, aunque la Junta Administradora podría proponer y sugerir modificaciones. La Junta quedaba autorizada para gestionar préstamos hasta la suma de $\$ 25.000$. y por encima de esta cifra requería autorización del Concejo Municipal.

La nueva organización creada estaba constituida por una Junta Administradora en la cual el Concejo delegaba las funciones propias del manejo de los servicios a cargo del Municipio y por un auditor permanente nombrado por el Concejo. El Gerente General tenía bajo su dirección tres jefes de sección para cada uno de los servicios: Sub-Gerente de Acueducto, Administrador de la Plaza de Mercado y Administrador del Matadero Municipal.

\section{La recuperación}

El crecimiento económico, que se interrumpió en el período 1929 a 1932, comenzó su recuperación a partir de 1933.

La reiniciación de las obras públicas, la continuación del movimiento del café de exportación y la creación de empresas manufactureras, algunas de ellas de capital extranjeros, reactivaron la actividad económica de Cali. 
En este período las exportaciones cafeteras del país continuaron creciendo y reorientando su flujo -vía Cali- hacia Buenaventura. La capital vallecaucana recibió, pues, los impactos dinamizadores de esta actividad. Es el período en que Buenaventura comienza a superar a Barranquilla en la cantidad de café despachado al exterior (Ocampo, 1981, p. 129).

Las inversiones y los gastos de la Empresa del Ferrocarril del Pacífico que durante la crisis se restringieron, incluso más aceleradamente que el descenso de los ingresos, comienzan a elevarse a partir de 1933, siguiendo un comportamiento similar al de la cantidad de carga y al número de pasajeros movilizados.

Esta reactivación del gasto que ocurrió no sólo en los Ferrocarriles del Pacífico, además, en el Departamento y en el Municipio, incidió en el incremento de la demanda y en el crecimiento económico del Valle y de Cali.

El nuevo gobierno de Olaya Herrera, decidió establecer desde 1931 el control de cambios, de tal manera, que el crédito procedente de emisiones no podía orientarse a la adquisición de divisas, ni afectar las reservas internacionales. Igualmente, se ampliaron los créditos del Banco de la República al gobierno y se reactivó la inversión y el gasto público. Pero además, se incrementó el crédito privado estableciendo límites a las tasas de interés y se ampliaron los plazos. Esta política llevó a que desde finales de 1932 comenzaran a aparecer signos de reactivación (Bejarano, 1995, p. 116).

En el contexto de los años anteriores a la Segunda Guerra Mundial, bajo las condiciones propicias para la sustitución de importaciones, irrumpe con celeridad en la ciudad una industrialización de nuevo tipo claramente diferenciada de las rudimentarias manufacturas anteriores que producían bienes de consumo. En este período aparecen en el panorama industrial nuevos productos (químicos, farmacéuticos, de caucho, papeles y cartón, nuevos materiales de construcción y productos alimenticios procesados) con tecnologías nuevas, mayor tamaño de escala y de planta (Vásquez, 2001, pp. 183-184).

Pero, además, se inicia el flujo de inversión extranjera en el área de la ciudad: Maizena (1933), Croydon (1937), Sidney Ross (1942), Good Year (1944), Cartón de Colombia (1944), E.R. Squibb \& Sons International Corporation (1944) y Eternit del Pacífico (1945). Pero, también, se montaron empresas de capital Nacional: Textiles El Cedro (1937) y Cementos del Valle en Puerto Isaacs (1938).

La creación de la empresa cementera fue fundamental para sustentar la reactivación de la construcción en la ciudad. El número de viviendas de Cali pasó de 7.700 en 1933 a 18.116 en 1945 lo que significó una elevada tasa de crecimiento anual (7.8\%). "En el año 1935 principió la reacción económica después de la crisis 19301934. Con la reacción vino también el aumento de la construcción de edificios en la ciudad, mejoró el precio de la propiedad raíz, la valorización de los terrenos en los barrios y urbanizaciones nuevos y en sus vecindades" (Boletín Estadístico Municipal, 1945). 
En el lapso de 12 años (1933-1945) se construyeron: La base aérea El Guabito (que surgió debido la necesidad de convertir a Cali en centro de operaciones de la fuerza aérea en el conflicto bélico con el Perú), la Escuela de Artes y Oficios Antonio José Camacho, el Puente España, la nueva fachada de la Catedral, el edificio de la Compañía Colombiana de Tabaco, el Palacio Obispal, La Antigua Gobernación, los Talleres de Chipichape (1929-1934), el edificio del Colegio Berchmans, el hipódromo de Versalles, el Colegio de la Sagrada Familia, el edificio Gutiérrez Vélez, la Nueva sede del colegio de Santa Librada, el Club San Fernando, el Colegio María Auxiliadora, se inicia el Hospital Departamental, el Templete Eucarístico, el Conservatorio, y finalmente al terminar el período, el Hotel y Teatro Aristi, el edificio Merchant, el Hotel Columbus y el Teatro Colón.

Las nuevas empresas manufactureras y la construcción jugaron un papel de enorme importancia en la dinámica del producto interno de la ciudad y en el empleo. En el período 1933-1945 la tasa de crecimiento anual del producto (13.77\%) superó a la del empleo $(9.27 \%)$, de tal manera que por cada $1 \%$ de crecimiento en el empleo el producto creció a $1.49 \%$. El aumento de la productividad se atribuye a la industria manufacturera -tanto en las empresas extranjeras como en las nacionales- que introdujeron cambios técnicos e innovaciones.

Este acelerado crecimiento económico incidió en el crecimiento real de los tributos municipales como los de industria y comercio, aseo, alumbrado público, pero especialmente el impuesto predial. "De 1941 en adelante se inició un gran movimiento comercial en la propiedad raíz consignado en las cifras registradas por valor de las operaciones notariales. A esto se agrega la organización en el recaudo del impuesto predial y los servicios que lo complementan y a la tecnificación de la oficina de catastro. Con todo ha sido tan brusco el ascenso del índice que refleja el recaudo de los impuestos catastrales en el último decenio, que parece indicar una época de progreso excepcional, quizá debida a la desvalorización de la moneda o acaso a la inflación en el precio de las cosas" (Boletín Estadístico Municipal, 1945).

Durante la reactivación (1933-1945) la tasa de crecimiento anual de la población de la cabecera municipal (7.13) aumentó respecto a la del período de la crisis (6.372), debido especialmente al movimiento inmigratorio.

De 1933 a 1945 el área construida legalmente, o con licencia, ascendió a 126 hectáreas pero la ciudad se amplió en 435 hectáreas que incluían vías, espacios públicos, zonas verdes y deportivas, además de barrios ilegales que comenzaban a expandirse masivamente (Terrón Colorado, Pueblo de Lata, Porvenir, Benjamín Herrera y Siloé que empezaba a conformarse) continuando en este período (19331945) el proceso iniciado en los años 20 de una expansión urbana en fragmentos por fuera del casco urbano tradicional ${ }^{1}$ y que traspasaban el río Cali hacia el norte

\footnotetext{
${ }^{1}$ El casco urbano tradicional estaba delimitado por las actuales calles $5^{\text {a }}$., el río Cali, la calle 25 y la carrera 15. Cfr. Vásquez, E. Historia de Cali en el siglo XX, op.cit. cuadro. p. 139.
} 
(Granada. Juanambú, Centenario) y la línea férrea (Jorge Isaacs, Santander) y también en torno al camino del sur (San Fernando, Alameda. Guayaquil).

Igualmente en el período 1933-1940 se fueron creando pequeños segmentos dispersos de rancheríos a lo largo de la salida a Palmira (carrera primera) en los actuales barrios Popular, Olaya Herrera, Marco Fidel Suárez y Fátima. En el camino a Yumbo "al otro lado del río Cali" se ampliaron los barrios Granada, Juanambú, Centenario y aparecieron Versalles, San Vicente, Santa Mónica y la Campiña. Pero también aparece el barrio Bretaña como continuación del Alameda, Bellavista en el camino a Pichindé y Belalcázar en la salida del camino a Navarro, los barrios Benjamín Herrera e Industrial por la salida a Candelaria traspasando la vía férrea. Los fragmentos dispersos se localizaron a las salidas de las vías a Palmira (carre-

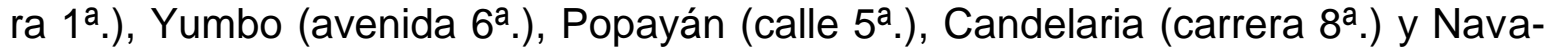
rro (Calle 15). Fue la expansión posterior de estos fragmentos o barrios dispersos, y la creación de nuevos barrios en los intersticios vacíos entre esos barrios, lo que fue haciendo compacta la ciudad durante el período de la post-guerra.

Con el desarrollo de la industria, el comercio y los servicios, las tierras e inmuebles del casco tradicional, especialmente los localizados en torno a la Plaza de Caicedo, fueron objetos de crecientes demandas con el objeto de localizar allí los nuevos usos del suelo promovidos por el desarrollo. De tal manera que crecieron los precios de la tierra en el núcleo urbano central y las expansiones urbanas se localizaron en este período en las salidas viales de la ciudad con precios del suelo inferiores (Aprile-Gniset,1992, p. 167).

El acelerado crecimiento económico de Cali durante el período (134.8\%) provocó una elevada tasa de crecimiento demográfico en la ciudad $(7.13 \%)$ debido fundamentalmente a la población inmigrante que creció a una tasa aún mayor. En esta acelerada dinámica de crecimiento económico, la actividad constructora implicó un rápido crecimiento de las viviendas acumuladas (7.4\% anual) y de la expansión del área urbana (7.8\% anual). Ante este crecimiento urbano inusitado, los servicios públicos comenzaron a retrasarse. La generación y suministro de energía y de agua potable que eran abundantes en el período anterior, experimentaron un rezago, en tanto que la cobertura y calidad de los servicios de alcantarillado y teléfonos disminuyeron sensiblemente.

\section{Los servicios públicos}

En materia de acueducto en este período, avanzaron las matrices norte y sur. En San Antonio se construyeron filtros y se amplió la capacidad nominal de 0.476 M3/seg. a $0.578 \mathrm{M} 3 / \mathrm{seg}$. (1942) y el mismo año se construyó el tanque de San Antonio II aumentando la capacidad de almacenamiento de 7.500 M3 a 15.000 M3. Pero esta ampliación de la capacidad nominal y la extensión de las matrices de distribución resultaron insuficientes ante la expansión urbana. La cobertura había caído de $90.3 \%$ al $72.9 \%$ para 1945 , por cuanto las viviendas totales urbanas crecieron más rápidamente que las viviendas con servicio, a la vez que se que 
se presentó un aumento del consumo per-capita de la población, que pasó de 307 litros diarios en 1933 a 370 en 1945.

Luego entonces se presentó una concentración social del consumo: el consumo total creció a una tasa anual de $6.93 \%$ en el período y la cobertura del servicio disminuyó, de tal manera que se elevó el consumo per-cápita de la población servida. Fundamentalmente no fueron servidos los habitantes de los nuevos barrios no legales que irrumpieron durante el período, algunos de los cuales (por ejemplo, Terrón Colorado y las primeras ocupaciones de Siloé) se ubicaban a niveles o cotas que impidieron llevar el servicio en esa época; por otra parte, no pertenecían legalmente a la zona urbana. La crisis de abastecimiento que comienza a gestarse desde 1934 no pudo ser revertida con las obras de San Antonio en 1942 (tanque II y filtros) ni con el control del consumo por medio de colocación de medidores (1943).

La construcción de esta etapa del acueducto fue de gran significado para la ciudad como se desprende de la crónica relatada en Despertar Vallecaucano (№ 103, agosto 1990, p. 35):

Como la ciudad Santiago de Cali estaba en crecimiento vertiginoso y reclamaba unas nuevas redes de suministro con aguas más completas y abundantes, entonces la Junta Constructora inició otro plan de obras muy importante, y en noviembre de 1927 comenzó a emprender la segunda etapa. Este proyecto fue confiado al famoso ingeniero Geo C. Bunker, quien tenía sus oficinas en Panamá, y asignaron como ingeniero asistente al doctor Lewis Moore, quien a la vez era residente para este contrato que se organizó con todas las técnicas modernas de aquella época, para que instalaran un vertedero y tres cámaras de mezcla y un tanque de sedimentación con ocho filtros, tipo americano, con una producción de suministro de 33.000 metros cúbicos de agua y dos instalaciones de aireación, además de un tanque con capacidad de 7.500 metros cúbicos, y con una instalación de bombeo para el lavado de los correspondientes filtros con capacidad de 200 metros cúbicos, además de la construcción de un edificio para ubicar la maquinaria para los filtros de purificación y para el laboratorio donde se harían los análisis de agua, así como una casa para el administrador de la planta. Hoy en día permanecen todas estas instalaciones y están prestando sus servicios a cabalidad y buen funcionamiento, después de estar 59 anos sirviendo a la ciudad.

La Junta contrató directamente al ingeniero doctor Francisco Ospina, para que efectuara las siguientes obras complementarias: una bocatoma sobre el río Cali, por medio de un canal de desagüe que saliera del barrio Bellavista, construcción que se realizaría mediante un túnel cuyo recorrido mide aproximadamente hoy más de un kilómetro. Este trabajo era realizado para evitar unas filtraciones que estaban saliendo por aquella época de la bocatoma que quedaba por detrás de la estatua de Belalcázar, terrenos que fueron de la familia Guerrero y comprados posteriormente por el señor Roberto Arboleda, quien urbanizó ese sector. Con el ensanche de la Avenida Belalcázar por una ampliación de la carretera para los juegos del ano 36, sacaron mucha banca de tierra que debilitó la obra realizada por el Acueducto Municipal, y poste- 
riormente comenzaron las filtraciones a que hago referencia, para perjudicar las casas del barrio El Peñón, más aún las que quedaban recostadas a la loma de Belalcázar. Este hecho fue lo que motivó la construcción del "Túnel de Bellavista" que fue una obra famosa realizada también por la administración del señor Luis Cifuentes Zúñiga.

Fue solemne la inauguración de la planta del Acueducto Municipal, a las 11:30 de la mañana, fue inaugurada la planta de purificación del Acueducto, acaso la obra más importante realizada en los últimos tiempos. Este acto revistió extraordinaria solemnidad (Despertar Vallecaucano, № 104, octubre 1990, p.34).

Los ingenieros Bunker y Ospina fueron los pioneros para que la ciudad tuviera agua, como la tienen hoy los diferentes barrios de le ciudad, y más beneficiados los de le parte alta con capacidad de 33.000 metros cúbicos de agua al día. En el año 1931 pasó el acueducto a regir directamente con la sigla EEMM, o sea, Empresas Municipales.

En el período 1933-1945 continuó la construcción de alcantarillados, pero los barrios ilegales -especialmente los ubicados en las laderas de los cerros- no fueron cubiertos por el servicio. El cubrimiento del alcantarillado marchó más lentamente que el del acueducto hasta el punto que en 1938 era muy amplia la brecha entre la cobertura del servicio de acueducto que era de $97.7 \%$, mientras la del alcantarillado de $78.7 \%$. Pero además siguió acentuándose el problema de las aguas sanitarias y pluviales combinadas que se vertían a los cauces naturales inmediatos a la ciudad (río Cali, quebrada La Sardinera. etc.), ocasionando impactos adversos en la salubridad especialmente en las áreas bajas del oriente de la ciudad, además de los problemas de sedimentación, obstrucción y filtraciones de las redes de alcantarillado.

De otra parte, si bien la capacidad de generación eléctrica en el período de 1929 a 1933 superaba la demanda efectiva, a partir de 1938 resultó insuficiente para atender a la industria en expansión, el crecimiento de las áreas residenciales y del desarrollo de las actividades terciarias en la ciudad. En 1930 la ciudad disponía de 3.400 kilovatios "que eran suficientes para abastecer las necesidades de la población...." En la misma época cuando Cali empezaba ya a perfilarse como urbe populosa, la demanda máxima de energía para la pequeña área metropolitana era de $1.200 \mathrm{kw}$. De suerte que la capacidad total sólo vino a quedar copada por allá en 1938..." (Paredes, 1965).

Entre 1930 y 1938 la generación permaneció constante (3.400 Kw.), en tanto que la población urbana creció en $60 \%$. Por lo tanto, la generación por habitante cayó de 58 a 37.5 vatios, situación que continuó hasta 1954 y que no se había logrado superar con la planta diesel II puesta en funcionamiento en 1947. Las manifestaciones de la prensa eran claras tal como se puede colegir de las siguientes citas: "falta energía para atender las necesidades actuales y para su desarrollo futuro que ha sido detenido en forma que afecta hondamente sus intereses, muy especialmente en cuanto se selecciona con el incremento de la industria" (Diario del 
Pacífico, julio 26 de 1941). "Se ha agudizado en estos días el problema de la energía; es el más grave problema de la ciudad, y a su solución deben concurrir todas la fuerzas sociales... Cali presenta así el aspecto de un villorrio infeliz en donde no hay manera de lograr nada que se relacione con la energía y la luz eléctrica" (Diario del Pacífico, agosto 22 de 1941). "La ciudad soporta en materia de luz y energía el peor de lo servicios... esto pone en peligro... el futuro industrial y económico de Cali, ciudad cotejada ya desfavorablemente con otras que no deberían superarla en ninguna forma" (Diario del Pacífico, septiembre 13 de 1941).

Se habían buscado varias alternativas, pero no se realizaron, como el de la planta de La Caja (utilizando los ríos las Nieves y Pichindé) o el de la Central Hidroeléctrica de El Palo que fueron ordenados por el Concejo, pero cuyos estudios demostraron ser insuficientes para solucionar el problema. También por Acuerdo $\mathrm{N}^{\circ}$. 6 de 1941 el Concejo decidió "cuestión vital para el desarrollo de la ciudad... la adquisición de todo lo concerniente a establecer en Cali un servicio eléctrico de propiedad del municipio, en sus aplicaciones de luz, fuerza y calor" (Vásquez, 2001, p. 218).

Afectada por las críticas del debate, la Compañía Colombiana de Electricidad (CCE) había adquirido en 1931 la Planta del río Nima (que alimentaba a Palmira) y adicionó temporalmente $740 \mathrm{kw}$. generados en esa planta para atender el exceso de demanda en Cali mediante la interconexión de las dos ciudades. En 1943 construye Nima II elevando la capacidad en 2.350 kw., sin embargo, no se logró compensar el enorme desequilibrio existente.

A finales de la década de los años veinte, la Compañía Colombiana de Electricidad (De la Pedraja, 1985, pp. 137-144) se vio enfrentada a un gran debate por su presencia en el país. En realidad se trataba de una compañía norteamericana que en 1927 ostentaba una impresionante lista de adquisiciones (Barranquilla, Santa Marta, Ciénaga, Aracataca, en la costa Caribe; Honda, Girardot, Zipaquirá, en la zona central; Buenaventura, Palmira y Cali en el Valle del Cauca) y que desde su posición predominante pretendía con mínimas inversiones lograr el máximo en utilidades exportables. En su empeño chocó con los controles de cambio que el gobierno nacional se vio impelido a imponer justo en esos años y al no poder exportar su producto (como en el caso de Standard Oi) tenía enormes dificultades para exportar sus utilidades. Esta actitud explicaba el hecho de que las plantas operaran a plena capacidad y, sin embargo, no satisfacieran las demandas de energía eléctrica; se sometía así a un deterioro del equipo y no se satisfacían las necesidades. Esa situación provocaba fuertes controversias; pero en algo contribuyó la compañía muy positivamente: muy temprano concluyó que era necesario desarrollar una red que interconectara las principales ciudades del país y dio así nacimiento a la idea de la interconexión nacional, la cual solo vino a fructificar en la década de los años setenta. La empresa no pudo nunca superar la resistencia para adquirir las Empresas Unidas de Energía Eléctrica de Bogotá y luego en los años treinta y cuarenta la disposición del Estado frente a la inversión extranjera y la necesidad de su intervención en la economía cambió radicalmente y se produjo la ola de nacionalizaciones (o mas bien municipalizaciones) de empresas de servicios públicos de los años treinta y cuarenta. 
Después de los proyectos que fracasaron, se pensó en la hidroeléctrica de Anchicayá. En 1943 la prensa manifestaba que "hay que volver la mirada al río Anchicayá puesto que ya existen estudios que plantean su viabilidad" (Diario del Pacífico, abril 6 de 1943). Fue así que en 1944 el Municipio de Cali, el Departamento del Valle y la Nación decidieron la constitución de la empresa y la construcción de la Hidroeléctrica de Anchicayá-Chidral, la cual entró en funcionamiento en 1954.

La persistente insuficiencia de la oferta energética por parte de la CCE obligó a la empresas particulares a asumir -a altos costos- la generación propia, en tanto que la deficiencia del servicio eléctrico domiciliario y el malestar generalizado condujeron a que, por Acuerdo $N^{\circ} 34$ de 1944, finalmente se municipalizara la compañía y se anexara a las Empresas Municipales, tras un movimiento ciudadano que congregó a todos los estratos sociales y a las diversas agrupaciones políticas. Entre los dirigentes que lideraron el traspaso de la empresa norteamericana al Municipio se encontraban Joaquín Borrero Sinisterra, Alfonso Barberena, Luís Palacios, Rubén Orozco Micolta e Ignacio A. Herrera. ${ }^{2}$ Otro sector de la opinión, encabezado muy visiblemente por el diario el Relator (y muy esencialmente por Jorge Zawasdky) defendía intensamente a la CCE, lo que le ganó muchas antipatías por la época. $^{3}$

El servicio telefónico manejado por la Compañía Telefónica del Pacífico tampoco tuvo un desempeño adecuado a la dinámica del crecimiento económico y urbano de Cali durante el período 1933-1945. Las quejas eran abundantes como se puede ver en las Charlas de Domingo Ramos: "No hay quien no tenga quejas del servicio telefónico. Las telefonistas demoran a veces hasta cinco minutos en contestar una llamada y se ponen furiosas cuando se les mueve la palanca para ver si despiertan" (Despertar Vallecaucano, № 109, octubre de 1991, p. 16).

En 1939 la compañía Telefónica del Pacífico planteó un proyecto, que fue estudiado por el Concejo en marzo del siguiente año, consistente por una parte, en transformar gradualmente el sistema manual existente por uno automático y eliminar las líneas compartidas; por otra, rebajaba el número de teléfonos que debía ceder al municipio, mantenía las obligaciones tributarias y el monto de participación del municipio en la empresa. Pero a la vez el municipio garantizaba la rentabilidad para lo cual permitía la modificación de las tarifas.

La propuesta de contrato provocó una intensa discusión en el Concejo. Una comisión -denominada mayoría- lo apoyó, mientras que la denominada minoría (presidida por Rubén Orozco Micolta) no solo arremetió contra la propuesta con argumentos técnicos, sino que levantó la consigna de la necesidad de la municipaliza-

\footnotetext{
${ }^{2}$ Hacia 1925, Agapito Betancur, uno de los alcaldes de entonces, en su texto La ciudad; Medellín en el $5^{\circ}$ Centenario de su fundación, señala que esta oleada de municipalización o socialización de los grandes servicios públicos había sido iniciada en los Estados Unidos en 1909 y la idea fue aprovechada en esa ciudad también. Citado en Botero Herrera, Medellín 1980-1950. p. 107.

${ }^{3}$ Para mayores detalles ver: Silva G., J. E. El gran diario "Relator". En Calero Tejada, Á. Cali Eterno..., Op. cit., p. 195 ss.
} 
ción de la empresa (Gaceta Municipal, № 544, abril 9 de 1939). El momento era propicio para este tipo de posiciones: el estado benefactor, la defensa de lo público frente a lo privado eran temas recurrentes en el gobierno de Alfonso López Pumarejo. ${ }^{4} \mathrm{Si}$ bien el comienzo de la Segunda Guerra Mundial y las penurias financieras del municipio afectaban la posibilidad de la municipalización, el contrato, sustancialmente modificado, fue aprobado en junio 27 de 1944. En él se convino el traspaso de todos los activos de la empresa al Municipio el traspaso de la planta adquirida (de 5.500 líneas) y el establecimiento de una administración delegada hasta diciembre de 1947, cuando el traspaso y la automatización de la operación deberían estar cumplidos. Se establecía también la forma de amortización de la deuda contraída por el municipio, para lo cual éste emitió libranzas que fueron entregadas a un fideicomisario de la banca privada. Los términos del nuevo contrato fueron objeto nuevamente de oposiciones infructuosas por parte de Rubén Orozco Minolta.

A partir de la entrega, la empresa pasó a denominarse Empresa Telefónica del Municipio y quedó adscrita a las Empresas Municipales de Cali.

Fue éste un período en el cual surgió una crisis general de los servicios públicos en Cali que pretendió solucionarse con la municipalización de las empresas de servicios dentro de un ambiente que consideraba al estado como instrumento para solucionar las insuficiencias de la iniciativa privada para lograr cubrir amplios sectores de la población, o porque se comprobó que el tratamiento tarifario favorecía los intereses de unos accionistas y perjudicaba a otros sectores de la población o a la comunidad en general (Jaramillo, 2005, p. 4). La municipalización terminó por imponerse, no sin dificultades debidas a las prevenciones políticas, pero también a las dificultades económicas por las que atravesaba la sociedad colombiana y la local en especial.

No por último menos importante, hay que relacionar la creación del sindicato de trabajadores el 29 de mayo de 1937, en casa de Alcides Arcos en el barrio Alameda. Su primer presidente fue Jorge Navia Paz; pronto ingresaron a la Confederación Sindical de Colombia. En 1938 se fundó el primer fondo de empleados y pronto la cooperativa de trabajadores de la empresa que subsiste hasta hoy: COOTRAEMCALI (Barrios, abril de 1997).

\section{Bibliografía}

Fuentes documentales

Fajardo J. (julio 11 de 1921). Municipio de Cali. Descripción General. Gaceta Municipal, Nos. 312 y 313.

Acuerdo № 9 del 19 de agosto de 1912. (9 de abril de 1939). Gaceta Municipal, № 544.

\footnotetext{
${ }^{4}$ La Ley 126 de 1938 había declarado de utilidad pública la adquisición por parte de la nación, los departamentos o los municipios de las empresas que prestaran en el territorio nacional servicios públicos.
} 
Acuerdo № 18 de 1915.

Acuerdo 45 de 1924.

Boletín de Estadística Departamental (enero 2 de 1922), Vol. I, № 1.

Boletín Estadístico Municipal. (1945). Cali: Contraloría Municipal de Cali.

Posada Callejas, J. (1918). Libro Azul de Colombia. New York: J. J. Little \& Ives Co.

Cómo nació la urbanización San Fernando. Mayo - jun 1987). Despertar Vallecaucano, № 20.

Caro Copete, J. (sept 1989). Las pilas de Cali. Despertar Vallecaucano, № 99.

Despertar Vallecacucano (agosto 1990). № 103.

Despertar Vallecaucano. (oct. 1991), № 109.

Diario del Pacífico. (Julio 26 de 1941).

Diario del Pacífico. (Agosto 22 de 1941).

Diario del Pacífico. (sept. 13 de 1941).

Diario del Pacífico. (abril 6 de 1943)

Proyecto de Contrato para la instalación de una Planta de Teléfonos Automáticos. (abril 9 de 1939). Gaceta Municipal, № 544.

\section{Fuentes bibliográficas}

Aguayo, A. (mayp 1988). El pintoresco tranvía que hizo la felicidad de los caleños en 1910. Despertar Vallecaucano, № 93.

Almario, O. (s.f). Nuevas regiones políticas y culturales en el occidente de Colombia. En Flórez, L. Prácticas e imágenes de modernización y modernidad en el Valle del Cauca. Ebenda.

Aparicio Navia, A. (dic 1996 - ene 1997). El acueducto de Cali, y un suceso consecuencial. Despertar Vallecaucano, № 135.

Aprile-Gniset, J. (1992). La ciudad colombiana, T. II. Bogotá: Banco Popular.

Barrios López, A. (abril 1997). Reseña histórica del sindicalismo. Cali: Sintraemcali, (mecanografiado). 
Calero Tejada, Á. (1983). Cali tuvo tranvía urbano. En Calero Tejada, Á. Cali Eterno; la Ciudad de Ayer y de Hoy. Cali: (s.e)

Castrillón, D. (1981). Manuel Carvajal Sinisterra y el Desarrollo. Bogotá: Banco del Estado.

De la Pedraja Tomán, R. (1985). Historia de la energía eléctrica en Colombia, 1537-1930. Bogotá: El Áncora.

Eder, P. J. (1958). El fundador, Santiago M. Eder. Bogotá: Antares, 1958.

Estupiñán C., L. M. (abril 1985). Eentrevistando a Carlos Gamboa, Cuando las calles las iluminaban con farolitos. Despertar Vallecaucano, №. 83.

Gómez Benítez, P. (1979). El Camino de Buenaventura. Cali: Universidad del Valle, Tesis Programa de Historia.

Jaramillo Panesso, R. (2005). La encrucijada de los servicios públicos. Norma: Bogotá, 2005.

Jiménez E., Y. \& Bonilla, R. (s.f). Acueducto y Alcantarillado; Cali 1910-1970. Cuadernos CITCE, Serie Investigaciones \#5.

Kalmanovitz, S. (1985). Economía y Nación. Bogotá: Siglo XXI Editores.

Ocampo, J. A. (1981). El desarrollo económico de Cali en el siglo XX. En Santiago de Cali - 450 años de Historia. Cali: (s.e.).

Ocampo, J. A. \& Montenegro, S. (1982). La crisis mundial de los años treinta en Colombia. Desarrollo y Sociedad, № 7.

Ocampo, J. F. (1984). Colombia y la economía mundial, 1830-1910. Bogotá: Siglo XXI Editores.

Ordóñez Burbano, L. A. (1995). Industrias y empresarios modernos, Cali 19101945. Cali: Universidad del Valle.

Paredes Cruz, J. (1965). El Valle del Cauca; su realidad económica y cultural.

Posada Posada, C. E. (1989). La gran crisis en Colombia: el periodo 1928-1933. En: Nueva Historia de Colombia (NHC), Vol. V. Bogotá: Editorial Planeta, Bogotá.

Rodríguez, O. (1973). Efectos de la gran depresión sobre la industria colombiana. Bogotá: Tigre de Papel.

Valencia Llano, A. (1988). Estado Soberano del Cauca; Federalismo y 
Regeneración. Bogotá: Banco de la República.

Valencia Llano, A. \& Zuluaga, F. (1992). Historia regional del Valle del Cauca. Cali: Universidad del Valle.

Vásquez B., E. (abril 1990). Historia del desarrollo económico y urbano en Cali. Boletín Socioeconómico, № 20.

Vásquez, E. et all. (1995). Periodización y relaciones de las variables urbanas en la ciudad de Cali, 1900-1990. Cali: CIDSE-EMCALI.

Vásquez B., E. (2001). Historia de Cali en el Siglo XX; sociedad, economía, cultura y espacio. Cali: (s.e).

Vélez, H. (1996). La disolución del Gran Cauca. En Valencia Llano, A. (ed.), Historia del Gran Cauca, Historia Regional del Suroccidente Colombiano. Cali: Universidad del Valle:

Recibido: 23 de febrero de 2010.

Aprobado: 11 de mayo de 2010. 